\title{
STUDI PERTAMBAHAN PANJANG SULUR LIANA BERDAU LEBAR (Merremia peltata) DI AREAL KAMPUS POLITEKNIK PERTANIAN NEGERI SAMARINDA
}

\section{INCREMENT STUDY OF THE LENGTH OF BROAD LEAVED LIANA (Merremia peltata) IN THE AREA OF STATE AGRICULTURAL POLYTHECHNIC OF SAMARINDA}

\author{
M.Fadjeri $^{1 *}$,Emi Malaysia ${ }^{1}$, Dwinita Aquastini ${ }^{1}$ \\ ${ }^{1}$ Politeknik Pertanian Negeri Samarinda, Kampus Gunung Panjang, JI. Samratulangi, \\ Samarinda, Indonesia \\ *fadjeriedris@gmail.com
}

\begin{abstract}
The purpose of this research is to find out the increase in the length of long Liana Broad-leaved tendrils (Merremia Peltata) in the Area of Samarinda State Agricultural Polytechnic Campus. The research was conducted for 2 months in the area Campus of Agricultural Polytechnic State Samarinda which includes preparation and marking activities of selected liana, making ajir, wrapping liana to stick where to vine, data retrieval, data processing and reporting. The data taken in this study are: (1) Increase in the length of tendrils Liana Broad-leaved (Merremia Peltata) that is deliberately allowed to creep above the surface of the ground (treatment 1st); (2) increase in the length of tendrils Liana Broad-leaved (Merremia Peltata) deliberately bought on stick where to vine (treatment 2nd); dan (3) the number of Liana twists on each stick where to vine.Sampling is done intentionally (purposive sampling), namely by searching for liana in campus areas that are eligible for use in research. The number of samples for lyanas that are deliberately left to creep above ground level and deliberately wrapped around stick where to vine each 30 individuals. The results of the study are as follows: (1) the increase in the length of tendrils Liana Broad-leaved (Merremia Peltata) that is deliberately allowed to creep above the ground (treatment 1st) is the amount of increase in tendril length $12945.10 \mathrm{~cm}$ and average $431.50 \mathrm{~cm} / 6$ weeks;(2) increase in the length of tendrils Liana Broad-leaved ( Merremia Peltata) deliberately bought on ajir (treatment 2) is the amount of increase in tendril length $12835.10 \mathrm{~cm}$ and average $427.84 \mathrm{~cm} / 6$ weeks; and (3) the increase of Liana Broad Leaved (Merremia Peltata) in stick where to vine is the amount of 214.00 twists and an average of 7.13 twists.
\end{abstract}

Keywords : Broad leaved liana (Merremia peltata), Increase in length of tendrils, Stick where to vine

\section{PENDAHULUAN}

Mengingat pembangunan $\mathrm{HTI}$ secara besar-besaran akan merangsang timbulnya hama penyakit dan gulma, maka diperlukan perencanaan yang matang, baik perencanaan ekonomis maupun perencanaan teknis di lapangan, mulai dari pengadaan bibit, penyiapan lahan, penanaman, sampai pemeliharaannya, sehingga tidak mengundang berbagai permasalahan baru di luar dugaan semula.

Menurut Yunasfi (2007), gulma adalah semua jenis vegetasi tumbuhan yang menimbulkan gangguan pada lokasi tertentu terhadap tujuan yang diinginkan manusia atau sejenis tumbuhan yang individu-individunya seringkali tumbuh pada berbagai tempat yang menimbulkan kerugian pada manusia.

Di dalam Hutan Tanaman Industri ( $\mathrm{HTI})$, gulma tersebut tergolong liana berkayu yang mempunyai daun lebar yang dikenal dengan nama latin Merremia peltata, biasanya dengan cepat mengganggu pertumbuhan tanaman pokok secara mekanis yaitu dengan cara membelit tanaman pokok mulai dari akar sampai tajuk dengan sulurnya, sehingga tanaman pokok akan kalah bersaing dalam hal pengambilan cahaya, unsur hara ,air dan ruang tumbuh yang mengakibatkan tanaman pokok merana dan kemudian mati. 
Secara silvikultur Merremia peltata merupakan liana berdaun lebar dan tergolong jenis pionir, kemampuan reproduksinya cepat, tumbuhan ini akan hadir pada tempat terbuka baik dalam lingkungan hutan mapun di luar hutan , seperti kebun, lapangan terbuka, bangunan yang ditinggalkan dan tempat sejenis lainnya.

\section{METODOLOGI}

\section{Tempat Dan Waktu}

Penelitian dilaksanakan di areal Kampus Politeknik Pertanian Negeri Samarinda, Kelurahan Gunung Panjang, Kecamatan Samarinda Seberang. Penelitian dilaksanakan lebih kurang 2 bulan mulai tanggal 30 Januari 2018 sampai dengan 20 Maret 2018.

\section{Alat Dan Bahan}

Bahan yang digunakan dalam penelitian ini adalah vegetasi Liana Berdaun Lebar (Merremia peltata) yang tumbuh pada lokasi pengamatan. Sebanyak 30 sampel untuk masingmasing perlakuan.

Alat yang digunakan dalam penelitian ini adalah:
a. Meteran, untuk mengukur panjang Liana
b. Gunting stek, untuk memotong contoh material sampel Liana
c. Tali rafia, untuk membuat batasan masing-masing sampel Liana
d. Plastik, untuk pemberian nomor- nomor sampel Liana
e. Ajir, untuk membelitkan Liana.
f. Parang, untuk membuat ajir.
g. Alat tulis menulis.

\section{Prosedur Penelitian}

1. Orientasi lapangan dilakukan untuk mengetahui keadaan lokasi penelitian sekaligus untuk menentukan lokasi penelitian

2. Mempersiapkan peralatan penelitian untuk kelancaran penelitian

3. Mempersiapkan ajir dari kayu dengan diameter $5 \mathrm{~cm}$, panjang 1.5 $\mathrm{m}$
4. Pengambilan sampel dilakukan secara sengaja (purposive sampling)

5. Menentukan jenis Liana yang diamati sebanyak 60 sulur, terdiri dari
a. Perlakuan 1: 30 sulur sengaja dibiarkan merayap di atas permukaan tanah
b. Perlakuan 2: 30 sulur sengaja diikatkan pada ajir agar membelit dan merambat.

6. Pemberian tanda awal pengukuran pada ujung masing-masing sulur Liana berupa ikatan tali rapia pada sampel untuk masing-masing perlakuan.

7. Pemberian nomor pada tiap-tiap sulur Liana yang diamati.

8. Mengukur panjang sulur Liana untruk masing perlakuan setiap minggu sampai akhir pengamatan.

\section{Pengolahan Data}

Data yang telah dikumpulkan diolah dengan rumus rata-rata berdasarkan Pambudhi (1985), sebagai berikut:

1. Nilai Rata-rata Pertambahan Panjang Liana Berdaun Lebar (Merremia peltata)

$$
\bar{x}=\frac{\sum x_{\mathrm{i}}}{\mathrm{n}}
$$

Keterangan :

$\bar{x}=$ Nilai rata-rata pertambahan panjang seluruhnya Liana Berdaun Lebar (Merremia peltata)

$\sum x_{i}=$ Nilai pertambahan panjang seluruhnya

$\mathrm{N}=$ Jumlah sampel yang diamati

2. Nilai Rata-rata Pertambahan Panjang Liana Berdaun Lebar (Merremia peltata) tiap Satu Sulur Liana.

Keterangan:

$$
\bar{x}_{\iota}=\frac{\mathrm{p}_{2}-\mathrm{p}_{1}}{\mathrm{~W}}
$$

$\bar{x}_{\imath} \quad=$ Nilai rata-rata pertambahan panjang liana, untuk satu sulur Lliana Berdaun Lebar (Merremia peltata)

$\mathrm{P}_{1} \quad=$ Pengukuran awal.

P2 = Pengukuran akhir

$\mathrm{W}=$ Lamanya waktu pengamatan (hari) 
3. Rata-rata Belitan Liana Berdaun Lebar (Merremia peltata)tiap SatuTurus.

$$
\bar{x}_{l}=\frac{\mathrm{b} 1+\mathrm{b} 2+\mathrm{b} 3+\cdots+\mathrm{b}_{\mathrm{n}}}{\mathrm{n}}
$$

Keterangan :

$\overline{x_{l}}=$ Nilai rata-rata pertambahan panjang liana, untuk satu sulur Liana Berdaun Lebar (Merremia peltata)

$\mathrm{B}=$ Jumlah belitan

$\mathrm{N} \quad=$ Jumlah seluruh sampel

Dari hasil perhitungan rata-rata panjang sulur yang sengaja dibiarkan merayap di atas permukaan tanah dan sengaja dibelitkan pada ajir selanjutnya diselesaikan dengan langkah-langkah sebagai berikut:

1. Menghitung Nilai Simpangan Baku (SB)

$$
S B=\sqrt{\frac{\sum X^{2}-\frac{\left(\sum X\right)^{2}}{n}}{n-1}}
$$

Keterangan:

$$
\begin{array}{ll}
\text { SB } & =\text { Simpangan baku } \\
\sum x & =\text { Jumlah nilai individu } \\
\sum x^{2} & =\text { Jumlah individu yang } \\
& \begin{array}{l}
\text { dikuadratkan } \\
\mathrm{n}
\end{array}
\end{array}
$$

2. Menghitung Nilai Simpangan Baku Gabungan ( $\mathrm{S}_{\text {pooled }}$ )

$$
S_{\text {Pooled }}=\sqrt{\frac{\sum X_{1}^{2}-\frac{\left(\sum X_{1}\right)^{2}}{n_{1}}+\sum X_{2}^{2}-\frac{\left(\sum X_{2}\right)^{2}}{n_{2}}}{n_{1}+n_{2}-2}}
$$

Keterangan :

$\begin{array}{lll}\mathrm{S}_{\text {pooled }} & =\text { Simpangan baku } \\ \mathrm{n} & \text { Gabungan } & \\ \mathrm{n} & =\text { jumlah sampel }\end{array}$

3. Menghitung Nilai Kesalahan Baku Gabungan ( $\mathrm{Se}_{\text {pooled }}$ )

$$
S e_{\text {pooled }}=S_{\text {pooled }} \sqrt{\left(\frac{1}{n_{1}}+\frac{1}{n_{2}}\right)}
$$

4. Untuk mengetahui apakah hasil perhitungan rata-rata pertambahan panjang sulur dari kedua perlakuan terdapat perbedaan,maka diuji dengan kaidah sebagai berikut :

$H_{0}=\mu_{1}-\mu_{2}=0 \rightarrow$ tidak berbeda

$H_{A}=\mu_{1}-\mu_{2} \neq 0 \rightarrow$ berbeda

$$
T_{\text {hitung }}=\frac{\bar{X}_{1}-\bar{X}_{2}}{S e_{\text {pooled }}}
$$

Bila $T_{\text {hitung }}>\mathrm{T}_{\text {tabel }} \rightarrow \mathrm{H}_{0}$ ditolak dan $\mathrm{H}_{\mathrm{A}}$ diterima

Bila $T_{\text {hitung }}<\mathrm{T}_{\text {tabel }} \rightarrow \mathrm{H}_{0}$ diterima dan $\mathrm{H}_{\mathrm{A}}$ ditolak

\section{HASIL DAN PEMBAHASAN}

Hasil pengukuran panjang sulur

\begin{tabular}{|c|c|c|c|c|c|}
\hline \multirow{2}{*}{ Perlakuan } & \multirow{2}{*}{ Uraian } & \multicolumn{2}{|c|}{ Pengukuran (cm) } & \multirow{2}{*}{ Pertambahan (cm) } & \multirow{2}{*}{ Keterangan } \\
\hline & & Awal & Akhir & & \\
\hline \multirow[t]{2}{*}{1} & Jumlah & 172.50 & 13117.60 & 12945.10 & \\
\hline & Rataan & 5.75 & 437.25 & 431.50 & \\
\hline \multirow[t]{2}{*}{2} & Jumlah & 157.80 & 12992.90 & 12835.10 & \\
\hline & Rataan & 5.26 & 433.10 & 427.84 & \\
\hline
\end{tabular}
dan hasil perhitungan pertambahan panjang sulur Liana berdaun lebar (Merremia peltata) dapat dilihat pada

\begin{tabular}{|c|c|c|c|c|c|}
\hline \multirow[t]{2}{*}{ Perlakuan } & \multirow[t]{2}{*}{ Uraian } & \multicolumn{2}{|c|}{ Jumlah (belitan) } & \multirow{2}{*}{$\begin{array}{l}\text { Pertambahan } \\
\text { (belitan) }\end{array}$} & \multirow[t]{2}{*}{ Keterangan } \\
\hline & & Awal & Akhir & & \\
\hline 2 & Jumlah & 0 & 214.00 & 214.00 & \\
\hline & Rataan & 0 & 7.13 & 7.13 & \\
\hline
\end{tabular}
Tabel 1. Sedangkan hasil perhitungan pertambahan belitan sulur Liana berdaun lebar (Merremia peltata) dapat dilihat pada Tabel 2.

Tabel 1. Hasil Pengukuran dan Perhitungan Pertambahan Panjang Sulur Liana Berdaun Lebar (Merremia peltata)

Tabel 2. Hasil Perhitungan Pertambahan Belitan Sulur Liana Berdaun Lebar (Merremia peltata) 
Pertambahan sulur dan pertambahan belitan Liana Berdaun Lebar (Merremia peltata) yang cepat karena Liana mampu hidup pada semua kondisi tanah, baik tanah yang subur maupun yang miskin hara, sebagai mana yang diungkapkan oleh Moenandir (1988) dalam Kamariah (1993), bahwa gulma adalah tumbuhan yang mudah tumbuh pada setiap tempat mulai dari tempat yang miskin nutrisi sampai yang kaya nutrisi.

Menurut Najib dan Pratiwi (1990), Merremia peltata merupakan salah satu gulma berkayu yang sangat merugikan di daerah terbuka dan dapat menekan pertumbuhan anakan serta dapat menyebabkan kebakaran, hal ini disebabkan karena jenis ini merupakan gulma berdaun lebar yang dapat tumbuh baik di daerah terbuka. Jenis liana ini tumbuh merambat dan dapat menutupi tajuk serta melilit batang pokok yang mengakibatkan tanaman pokoknya terganggu cacat batang serta penurunan dan kualitas kayu, sehingga perlu dilakukan pengendalian secara kimiawi, mekanik maupun kultur teknis.

Hasil Uji-T pertambahan panjang sulur Liana Berdaun Lebar yang dibiarkan merayap di atas permukaan tanah dan sengaja dibelitkan pada ajir dapat dilihat pada Tabel 3.

Tabel 3. Hasil Uji-T Pertambahan Panjang Sulur Liana Berdaun Lebar Yang Sengaja Dibiarkan Merayap Di Atas Permukaan Tanah Dan Dibelitkan Pada Ajir.

\begin{tabular}{lrr} 
& Perlakuan 2 & Perlakuan 1 \\
\hline Mean & 427.836667 & 431.50333 \\
Variance & 1642.84585 & 906.73757 \\
Observations & 30 & 30 \\
Pooled & & \\
Variance & 1274.79171 & \\
Hypothesized & & \\
Mean & & \\
Difference & 58 & \\
df & & \\
t Stat & & \\
P $(T<=t)$ one-tail & 0.34614161 & \\
t Critical one-tail & 1.67155276 & \\
P $(T<=t)$ two-tail & 0.69228322 & \\
t Critical two-tail & 2.00171748 & \\
\hline
\end{tabular}

Berdasarkan hasil uji - T seperti yg tertera pada Tabel 3, baik uji satu arah maupun uji 2 arah ternyata tidak berbeda nyata pertambahan panjang sulur Liana Berdaun Lebar (Merremia peltata) dari 2 perlakuan, masing-masing terdiri dari 30 sampel yaitu yang sengaja dibiarkan merayap di atas permukaan tanah dan yang sengaja dibelitkan pada ajir.

\section{KESIMPULAN}

1. Rata-rata pertambahan panjang sulur Liana Berdaun Lebar (Merremia peltata) yang sengaja dibiarkan merayap di permukaan tanah adalah $431.50 \mathrm{~cm} / 6 \mathrm{ming} g \mathrm{u}$

2. Rata-rata pertambahan panjang sulur Liana Berdaun Lebar (Merremia peltata) yang sengaja dibelitkan pada ajir adalah adalah $427.84 \mathrm{~cm} .6$ minggu

3. Rata - rata pertambahan belitan Liana Berdaun Lebar (Merremia peltata) adalah 7.13 belitan

4. Pertambahan panjang sulur Liana Berdaun Lebar (Merremia peltata) yang sengaja dibiarkan merayap di atas permukaan tanah maupun yang sengaja dibelitkan pada ajir cenderung komulatif.

5. Hasil Uji-T terhadap pertambahan panjang sulur Liana Berdaun Lebar (Merremia peltata) yang sengaja dibiarkan merayap di atas permukaan tanah dan senagaja dibelitkan pada ajir adalah tidak berbeda nyata.

6. Jenis Liana ini diduga berpotensi mengganggu tanaman $\mathrm{HTI}$ maupun tanaman perkebunan mulai dari anakan sampai dengan tingkat pohon.

\section{DAFTAR PUSTAKA}

ARIEF, A. 1994. Hutan / Hakekat dan Pengaruhnya Terhadap Lingkungan. Yayasan Obor Indonesia. Jakarta.

HAMZAH, Z. 1976. Mikanika Ancaman Baru Bagi Tanaman Kehutanan. Laporan Lembaga Penelitian Hutan. No. 223. Bogor.

HAMZAH, Z. dan H. Daryono. 1979. Beberapa Jenis Gulma yang terdapat pada Persemaian- 
Persemaian Pinus Merkusi No. 301. Bogor.

HAMZAH, Z. dan H. Daryono. 1979. Studi Mengenai Gulma Eupatorium odoratum $L$ yang terdapat di hutan Jati ( Tectona grandis ). Laporan Lembaga Penelitian Hutan No. 312. Bogor.

ILYAS, S. 1987. Pertumbuhan dan Penanggulangan/Pemusnahan Jenis Liana pada Hutan Tanaman Industri PT. Kiani Lestari Batu Ampar. 21 hlm.

MARSONO, D. 1987. Prinsip-Prinsip Silvikultur. Edisi kedua. Gadjah Mada Universitas Pers. Jakarta.

NAZIF, M dan Pratiwi. 1990. Studi Ekologi Gulma pada Hutan Tanaman Industri di Kalimantan Selatan. Biotrop Bulletin. No. 534. 15-26 hlm.

NAZIF, M. 1992. Uji Efikasi Beberapa Jenis Herbisida Guna Pengendalian Gulma Dibawah Tegakan Mahoni. Biotrop Bulletin. No. 547. $13-28$ hlm.

PAMBUDHI, P. 1985. Diktat Kuliah Statistik I. Fakultas Kehutanan Universitas Mulawarman Samarinda. $75 \mathrm{hlm}$.

SIREGAR, C. A. 1987. Pengaruh Gulma terhadap Tumbuhan Lamtorogung ( Leucaena Leucocophala ). Biotrop Bulletin. No. $492.28-35 \mathrm{hlm}$.

SUDRADJAT, S. 1985. Pengaruh Beberapa Jenis Herbisida terhadap Pertumbuhan Gulma Borreria latifolia ( AUBL ) Schum di Kebun Percobaa Dramaga, Bogor. Biotrop Bulletin. No. 464. $38-46 \mathrm{hlm}$.

SUKMAN, Y. 1991. Gulma dan Teknik Pengendaliaannya.

Fakultas
Pertanian Universitas Sriwijaya. Palembang. $115 \mathrm{hlm}$.

SUHARTI, M. dan Dwi. A.S. 1978. Percobaan Pemberantaan Mikania micrantha dengan Menggunakan Herbesida Paraguat 20\% 2,4-D Amine $72 \%$ dan Glyphoseta 36\%. Laporan Lembaga Penelitan Hutan. No. 281. Bogor.

SUHARTI, M. 1979. Pengaruh Intensitas Cahaya terhadap Pertumbuhan dan Biomas Mikania micrantha. Laporan Lembaga Penelitan Hutan. No. 380. Bogor.

SUTIDJO. 1974. Dasar - Dasar IImu Pengendalian dan Pemberantasan Tanaman Pengganggu. Proyek Peningkatan Mutu Perguruan Tinggi IPB. Bogor. $79 \mathrm{hlm}$.

SYAHHRILLAH. 1989. Pertumbuhan Liana di Lahan Hutan Tanaman industri PT. Kiani Lestari Batu Ampar. Sekripsi Fakultas Kehutanan Universitas Mulawarman. Samarinda. $41 \mathrm{hlm}$.

TANGKETASIK, J. dan A. SARIDAN. 1989. Pemberantasan Merremia Peltata dengan Menggunakan Herbisida Gramaxone, Roundup dan Tordon 101 di PT. Inhutani I unit I Long Nah, Kalimantan Timur. Wanatrop. Vol. 4. No. 1. $43-50$ hlm.

TJITROEDIRDJO, S. 1984. Pengelolaan Gulma di Perkebunan PT. Gramedia Jakarta. Bogor. 79 hlm.

YUNASFI, 2007. Permasalah Hama,Penyakit dan Gulma dalam Pembangunan Hutan Tanaman Industri dan Usaha Pengendaliannya. Departemen Kehutanan, Fakultas Pertanian .Universitas Sumatera Utara 